\author{
А.И. Полищук, А.Ю. Маршалка \\ Кубанский государственный аграрный университет, \\ г. Краснодар, Россия \\ ОРГАНИЗАЦИЯ ПОДГОТОВКИ ВЫПУСКНЫХ \\ КВАЛИФИКАЦИОННЫХ РАБОТ БАКАЛАВРОВ \\ И МАГИСТРАНТОВ НА КАФЕДРЕ ОСНОВАНИЙ \\ И ФУНДАМЕНТОВ КУБАНСКОГО ГОСУДАРСТВЕННОГО \\ АГРАРНОГО УНИВЕРСИТЕТА
}

\begin{abstract}
На примере деятельности кафедры оснований и фундаментов (ОиФ) Кубанского государственного аграрного университета рассматриваются вопросы подготовки выпускных квалификационных работ бакалавров и магистрантов по направлению «Строительство». Приводится состав кафедры, осуществляющий подготовку бакалавров и магистров, порядок назначения руководителей и консультантов, а также выбор тем квалификационных работ; даются рекомендации по срокам выполнения основных этапов.

Ключевые слова: кафедра, преподаватели, выпускная квалификационная работа, дипломный проект (работа) бакалавра, магистерская диссертация, бакалавр, магистрант, магистр.
\end{abstract}

\author{
A.I. Polishchuk, A.Yu. Marshalka
}

Kuban State Agrarian University, Krasnodar, Russian Federation

\title{
ORGANIZATION OF TRAINING QUALIFIED EXHAUST-CATIONS WORKS BACHELORS AND MASTERS AT THE DEPARTMENT BASES AND FOUNDATIONS OF KUBAN STATE AGRARIAN UNIVERSITY
}

In an article on the example of the Department bases and foundations, Kuban State Agrarian University (KubGAU) discussed issues of preparation of final qualifying works bachelors and masters in "Construction". The composition of the department, which prepares bachelors and masters, the procedure for appointing directors and consultants, as well as the choice of subjects qualifying works; provides recommendations for implementation of the basic stages of maturity.

Keywords: department, teachers, graduate work, thesis project (work) bachelor, master's thesis, bachelor, master. 


\section{Общие сведения о кафедре}

Кафедра «Основания и фундаменты» (ОиФ) является структурным подразделением инженерно-строительного факультета Кубанского государственного аграрного университета (КубГАУ) и обеспечивает подготовку выпускных квалификационных работ по направлению «Строительство» (дипломных проектов для бакалавров, магистерских диссертаций для магистров). По состоянию на 01.05.2014 г. на кафедре ОиФ имеется 14 штатных единиц профессорско-преподавательского состава (табл. 1). В настоящее время на кафедре работают 22 сотрудника, в том числе 16 преподавателей (3 профессора, 4 доцента, 5 старших преподавателей и 4 ассистента) и 3 сотрудника учебновспомогательного персонала. Часть сотрудников работает по совместительству на $0,5-0,75$ ставки. Средний возраст сотрудников 39 лет, преподавателей -49 лет.

Т аблица 1

Состав кафедры «Основания и фундаменты» Кубанского государственного аграрного университета

\begin{tabular}{|c|c|c|c|c|c|}
\hline \multirow[b]{2}{*}{$\begin{array}{l}\text { № } \\
\Pi / \Pi\end{array}$} & \multirow[b]{2}{*}{ Показатели } & \multirow[b]{2}{*}{$\begin{array}{l}\text { Ед. } \\
\text { изм. }\end{array}$} & \multicolumn{3}{|c|}{ Численность сотрудников } \\
\hline & & & $\begin{array}{c}\text { 2011/2012 } \\
\text { учеб. год }\end{array}$ & $\begin{array}{c}\text { 2012/2013 } \\
\text { учеб. год }\end{array}$ & $\begin{array}{l}\text { 2013/2014 } \\
\text { учеб. год }\end{array}$ \\
\hline \multirow[t]{10}{*}{1} & Сотрудники, в том числе & \multirow{10}{*}{ чел. } & 28 & 25 & 22 \\
\hline & преподаватели: & & 15 & 16 & 16 \\
\hline & профессора & & 3 & 3 & 3 \\
\hline & доценты & & 4 & 4 & 4 \\
\hline & старшие преподаватели & & 4 & 6 & 5 \\
\hline & ассистенты & & 4 & 3 & 4 \\
\hline & Аспиранты & & 6 & 5 & 3 \\
\hline & Магистранты & & 4 & 5 & 7 \\
\hline & Соискатели & & 1 & 1 & - \\
\hline & Учебно-вспомогательный персонал & & 3 & 3 & 3 \\
\hline 2 & Средний возраст преподавателей & лет & 46 & 47 & 49 \\
\hline 3 & Средний возраст сотрудников & лет & 39 & 38 & 39 \\
\hline
\end{tabular}

На кафедре имеется аспирантура по специальности 05.23.02 «Основания и фундаменты, подземные сооружения». С 2011 г. кафедра ведет подготовку бакалавров и магистрантов по направлению «Строительство». В настоящее время на кафедре 7 магистрантов и 3 аспиранта. Окончили обучение в аспирантуре в 2012 г., но пока не защитились 4 аспиранта. 


\section{Организация подготовки дипломных проектов бакалавров}

Кафедра ОиФ обеспечивает подготовку дипломных проектов (работ) бакалавров по направлению «Строительство» [1] на инженерностроительном факультете, факультете заочного обучения, а также в филиале в г. Анапы. Ежегодно, начиная с 2013 года, на кафедре защищаются примерно 14-19 студентов-бакалавров, а с 2015 года будут защищаться по 50-55 человек. Этот учебный год (2013/2014) является переходным, и одновременно с подготовкой бакалавров кафедра обеспечивает подготовку инженеров по специальности «Промышленное и гражданское строительство» (ПГС); всего от 82 до 94 студентов в год (табл. 2).

Таблица 2

Данные о подготовке специалистов и бакалавров по направлению «Строительство» на кафедре оснований и фундаментов КубГАУ

\begin{tabular}{|c|c|c|c|c|c|c|c|c|}
\hline \multirow{2}{*}{$\begin{array}{c} \\
\text { № } \\
\Pi / \Pi\end{array}$} & \multirow{2}{*}{\begin{tabular}{|c} 
Структурное \\
подразделе- \\
ние универ- \\
ситета
\end{tabular}} & \multirow{2}{*}{$\begin{array}{c}\text { Специаль- } \\
\text { ность }\end{array}$} & \multirow{2}{*}{$\begin{array}{c}\text { Форма } \\
\text { обуче- } \\
\text { ния }\end{array}$} & \multirow{2}{*}{$\begin{array}{c}\text { Квалифи- } \\
\text { кация }\end{array}$} & \multicolumn{4}{|c|}{$\begin{array}{c}\text { Распределение защит ди- } \\
\text { пломников (чел.) по годам }\end{array}$} \\
\hline & & & & & 2012 & 2013 & 2014 & 2015 \\
\hline \multirow[t]{2}{*}{1.} & \multirow{2}{*}{$\begin{array}{l}\text { Инженерно- } \\
\text { строитель- } \\
\text { ный факуль- } \\
\text { тет }\end{array}$} & \multirow{2}{*}{$\begin{array}{l}\text { Промышлен- } \\
\text { ное и граждан- } \\
\text { ское строи- } \\
\text { тельство }\end{array}$} & \multirow[b]{2}{*}{ Очная } & Инженер & 17 & 30 & 21 & 20 \\
\hline & & & & Бакалавр & - & 19 & 7 & 25 \\
\hline \multirow[t]{4}{*}{2.} & \multirow{4}{*}{$\begin{array}{l}\text { Факультет } \\
\text { заочного } \\
\text { обучения }\end{array}$} & \multirow{2}{*}{\begin{tabular}{|l} 
Промышлен- \\
ное и граж- \\
данское стро- \\
ительство
\end{tabular}} & \multirow[b]{2}{*}{ Заочная } & Инженер & 37 & 21 & 25 & 12 \\
\hline & & & & Бакалавр & - & - & 2 & - \\
\hline & & \multirow{2}{*}{$\begin{array}{l}\text { Промышлен- } \\
\text { ное и граж- } \\
\text { данское стро- } \\
\text { ительство на } \\
\text { базе СПО }\end{array}$} & \multirow[b]{2}{*}{ Заочная } & Инженер & 16 & 12 & 12 & - \\
\hline & & & & Бакалавр & - & - & - & 15 \\
\hline \multirow[t]{5}{*}{3.} & \multirow{4}{*}{$\begin{array}{l}\text { Филиал } \\
\text { в г. Анапе }\end{array}$} & \multirow{4}{*}{$\begin{array}{l}\text { Промыш- } \\
\text { ленное и } \\
\text { гражданское } \\
\text { строительство } \\
\end{array}$} & \multirow{2}{*}{ Заочная } & Инженер & 12 & 12 & 11 & - \\
\hline & & & & Бакалавр & - & - & - & 10 \\
\hline & & & \multirow{2}{*}{ Очная } & Инженер & - & - & 3 & - \\
\hline & & & & Бакалавр & - & - & 5 & 5 \\
\hline & & & ИТОГО: & & $82 / 0$ & $94 / 19$ & $86 / 14$ & $87 / 55$ \\
\hline
\end{tabular}

Примечание. Данные по 2015 г. являются плановыми; дробью показано: числитель - общее количество защит; знаменатель - количество защит бакалавров. 
Общая организация дипломного проектирования студентовбакалавров возложена на деканат инженерно-строительного факультета и выпускающие кафедры. Обычно работа со студентамибакалаврами по вопросам их дипломного проектирования начинается с 5-го семестра. На этом этапе распоряжением заведующего кафедрой предварительно назначаются руководители дипломного проектирования. До начала дипломного проектирования деканатом, а также выпускающей кафедрой по распоряжению декана составляется график дипломного проектирования, информация о котором доводится до студентов. На этом этапе производится окончательное утверждение руководителей и тем дипломных проектов (дипломных работ). Руководители дипломных проектов назначаются заведующим выпускающей кафедрой, где дипломируются студенты, в соответствии с имеющейся учебной нагрузкой. Студенты имеют право самостоятельно выбирать выпускающую кафедру для дипломирования и руководителя дипломного проекта (дипломной работы) в пределах установленной деканатом учебной нагрузки на кафедре. Срок выполнения дипломного проекта с учетом времени на его рецензирование и защиту устанавливается графиком учебного процесса и составляет обычно 5-6 недель.

Темы дипломных проектов (дипломных работ) определяет выпускающая кафедра после прохождения студентами преддипломной практики. Студенты имеют право самостоятельно предлагать тему дипломного проекта с обоснованием ее актуальности и целесообразности. Руководителя дипломного проекта и тему дипломного проекта утверждают на заседании выпускающей кафедры до начала выполнения проекта в соответствии с графиком учебного процесса. Выпускающая кафедра определяет темы дипломных проектов (дипломных работ) в зависимости от направления учебного процесса и направления научной деятельности. Например, для кафедры «Основания и фундаменты» могут быть сформулированы следующие названия тем дипломных проектов для студентов-бакалавров:

1. Конструктивное решение фундаментов административного здания на лессовых просадочных грунтах.

2. Обоснование рационального вида фундаментов здания детского сада в г. Краснодаре.

3. Разработка варианта фундаментов из составных железобетонных свай в грунтовых условиях г. Анапы. 
4. Оценка грунтовых условий и обоснование вида фундаментов для строительства трехэтажного каркасного здания в г. Сочи и др.

Перед началом дипломного проектирования проводится специальная лекция для студентов-дипломников бакалавриата инженерностроительного факультета, где излагаются основные требования к оформлению пояснительной записки и листов графической части. Студент-дипломник несет полную ответственность за полученные результаты, качество выполнения расчетно-пояснительной записки и графической части, а также за соответствие сроков выполнения работы графику дипломного проектирования.

Выпускные квалификационные работы могут быть следующих видов:

- академический дипломный проект (в том числе с элементами научных исследований, а также реальный);

\section{- дипломная работа.}

Первый вид квалификационной работы - академический дипломный проект - является самостоятельной инженерной разработкой, посвященной решению конкретных технических задач. Второй вид квалификационной работы - дипломная работа - самостоятельное научное исследование научно-технической задачи для строительной отрасли. Дипломная работа является результатом научной деятельности студента на выпускающей кафедре.

Дипломный проект состоит из расчетно-пояснительной записки и графической части. Средний объем расчетно-пояснительной записки дипломного проекта составляет 80-100 страниц машинописного текста (формат A4, с одной стороны листа). Схемы и графики в пояснительной записке выполняются по ходу изложения материала, как правило, на отдельной странице. Расчетно-пояснительная записка должна состоять из следующих частей: титульный лист; содержание пояснительной записки; задание на дипломный проект (дипломную работу); введение; содержание разделов проекта; список использованных источников; приложения.

Объем графической части дипломного проекта должен составлять 5-6 листов формата A1 или 10-12 листов формата А2 либо представляться на листах форматах А3 в нужном объеме. Форма представления графической части дипломного проекта принимается выпускающей кафедрой. Объем графической части по каждой смежной 
кафедре устанавливает выпускающая кафедра в соответствии с заданием на дипломное проектирование. Расчетно-пояснительную записку и графическую часть дипломного проекта рекомендуется выполнять на компьютере с использованием текстовых редакторов и компьютерной графики.

Задание на дипломный проект (дипломную работу) выдает руководитель дипломного проекта и утверждает заведующий выпускающей кафедрой. Задание студенту-дипломнику выдается до начала дипломного проектирования. Поставленные в дипломном проекте задачи студент-дипломник должен согласовать с консультантами смежных кафедр (в первую неделю дипломирования), которые дают согласие консультировать предлагаемые разделы и подтверждают это подписью на бланке задания. Студент-дипломник обращается за консультацией на смежную кафедру с заданием на выполнение дипломного проекта, утвержденного заведующим выпускающей кафедрой. Для каждого студента-дипломника рекомендуется привлекать для консультаций одного-двух консультантов смежных кафедр. Решение по количеству консультантов смежных кафедр принимает выпускающая кафедра.

Если в академическом дипломном проекте планируется выполнение научных исследований либо реальных заданий за счет сокращения разделов смежных кафедр, то задание на такой дипломный проект должно быть утверждено (согласовано) на заседании Ученого совета инженерно-строительного факультета по представлению выпускающей кафедры. Бланк задания на дипломный проект в этом случае составляется выпускающей кафедрой, а его форма (содержание) может быть произвольной.

Если выполняется дипломная работа, то для таких квалификационных работ утверждается только научный руководитель. Консультанты смежных кафедр могут не привлекаться. Задание на дипломную работу, отражающее ее содержание, составляется в произвольной форме и утверждается на заседании выпускающей кафедры, а затем - на заседании Ученого совета инженерно-строительного факультета.

\section{Организация подготовки магистерских диссертаций}

Кафедра ОиФ обеспечивает подготовку магистерских диссертаций будущих магистров по направлению «Строительство» на инже- 
нерно-строительном факультете [2]. Подготовка магистерских диссертаций на кафедре ведется с 2011 г. За этот период успешно защитились 5 магистров (период 2011-2013 гг.) (табл. 3). С 2013 г. кафедра ведет обучение магистрантов по магистерской программе «Техническая эксплуатация и реконструкция зданий и сооружений». По состоянию на 01.05.2014 г. на кафедре обучаются 7 магистрантов, из них 1 магистрант - второго года обучения, а 6 - первого года обучения.

Таблица 3

Данные о подготовке магистров по направлению «Строительство» на кафедре оснований и фундаментов КубГАУ

\begin{tabular}{|c|c|c|c|c|c|c|c|}
\hline $\begin{array}{c}\text { Структурное } \\
\text { подразделе- } \\
\text { ние универ- } \\
\text { ситета }\end{array}$ & Направление & Квалификация & \multicolumn{5}{|c|}{$\begin{array}{c}\text { Распределение защит } \\
\text { магистрантов (чел.) } \\
\text { по годам }\end{array}$} \\
\cline { 3 - 8 } & & 2011 & 2012 & 2013 & 2014 & 2015 \\
\hline $\begin{array}{c}\text { Кафедра ОиФ } \\
\text { стронерно- } \\
\text { факультього }\end{array}$ & $\begin{array}{c}\text { Строитель- } \\
\text { ство }\end{array}$ & $\begin{array}{c}\text { Магистр техники } \\
\text { и технологии }\end{array}$ & $\mathbf{1}$ & $\mathbf{2}$ & $\mathbf{2}$ & $\mathbf{1}$ & $\mathbf{6}$ \\
\hline
\end{tabular}

Магистерская программа обучения состоит из двух частей - образовательная и научно-исследовательская. Для выполнения второй части назначается научный руководитель магистерской диссертации. В отдельных случаях, по решению выпускающей кафедры, по магистерской диссертации могут назначаться консультанты. Научный руководитель магистерской диссертации, а также консультанты назначаются заведующим выпускающей (ведущей) кафедрой из числа аттестованных сотрудников (докторов и кандидатов наук). Первая помощь магистранту в выполнении магистерской диссертации оказывается при выборе темы магистерской диссертации. Далее магистрант, совместно с научным руководителем, составляет индивидуальный план (график) работы на весь период обучения и задание на подготовку диссертации. На кафедре используется разработанный в КубГАУ бланк задания на выполнение диссертации для магистрантов, который служит основой для начала творческой работы. Бланк задания подписывает научный руководитель и магистрант. Задание на выполнение магистерской диссертации утверждается заведующим выпускающей кафедрой, а также деканом факультета. Все темы магистерских диссертаций рас- 
сматриваются на заседании ученого совета инженерно-строительного факультета после их утверждения на заседании кафедры.

Для установления контроля над ходом обучения магистранта в магистратуре, а также для оказания помощи магистранту в университете разработана методическая документация, которая имеется на кафедре (учебный план, магистерская программа, бланки индивидуального плана магистранта, бланки задания на выполнения магистерской диссертации и др.). Началом работы магистранта над магистерской диссертацией является утверждение ее темы, которое обычно происходит в первые три месяца обучения магистранта в магистратуре.

На кафедре выполняются магистерские диссертации, направленные на решение следующих научно-практических задач [2]:

- научно-исследовательских в полном объеме;

- проектных и проектно-изыскательских с разделом научных исследований;

- реконструкции и восстановления зданий с разделом научных исследований;

- реального обследования фундаментов, грунтов основания, надземных строительных конструкций и оценки их технического состояния;

- экспертизы проектной документации, обоснования принимаемых решений по вопросам строительства и реконструкции зданий и другие.

Тема магистерской диссертации выбирается соискателем совместно с научным руководителем, исходя из научных и практических интересов, склонностей, способностей магистранта. Допускается на первом этапе подготовки магистранта (первый год обучения) формулировать предварительное название темы, которая впоследствии уточняется.

Формулировка темы магистерской диссертации должна максимально кратко и однозначно отражать основную цель работы. Например, для магистерской программы «Техническая эксплуатация и реконструкция зданий и сооружений» могут быть сформулированы следующие темы магистерских диссертаций:

1. Совершенствование метода определения расчетного сопротивления грунта основания для проектирования фундаментов реконструируемых зданий. 
2. Разработка конструктивных решений вертикального армирования оснований для компенсации неравномерной деформации плитных фундаментов зданий.

3. Разработка подходов к проектированию усиления отдельно стоящих фундаментов инъекционными сваями в глинистых грунтах.

4. Совершенствование конструктивных решений фундаментов девятиэтажного жилого дома в городке «Нефтяников» (г. Горячий Ключ) в условиях плотной городской застройки;

5. Разработка конструктивных мероприятий по повышению надежности фундаментов реконструируемого здания школы в городе Кропоткине и др.

При подготовке магистерской диссертации обязательным условием является отчетность магистранта на заседании кафедры о выполнении графика учебного процесса. Кафедра регулярно заслушивает магистрантов и научных руководителей по работе над магистерской диссертацией. Магистерская диссертация обычно выполняется магистрантом самостоятельно, с учетом реализации отдельных частей работы на практике.

Магистерская диссертация состоит из пояснительной записки и презентации, представляемой в электронном виде и на бумажном носителе. Средний объем пояснительной записки обычно составляет 80110 листов машинописного текста формата A4 (с одной стороны листа). Рисунки, схемы, графики, как правило, выполняются на отдельных листах. Для магистрантов рекомендуется следующий состав пояснительной записки: титульный лист; задание на выполнение магистерской диссертации; оглавление пояснительной записки; введение; содержание разделов; список использованных источников; приложения.

Презентация обычно демонстрируется на большом экране, с использованием мультимедийного оборудования; ее объем составляет 20-25 слайдов. Обязательным условием является подготовка презентации на бумажном носителе, которая раздается членам Государственной комиссии (ГАК) во время защиты диссертации.

Защита магистерской диссертации является публичной, она происходит в торжественной обстановке перед членами Государственной аттестационной комиссии и присутствующими. Для доклада результатов проделанной работы магистранту обычно отводится 
10-12 минут. Затем задаются вопросы соискателю, зачитывается отзыв научного руководителя, отзыв рецензента и предоставляется слово магистранту для ответов на замечания. Оценка магистерской диссертации производится членами ГАК в закрытом режиме после обсуждения доклада магистранта и результатов его работы за период обучения в магистратуре.

\section{Библиографический список}

1. Федеральный государственный стандарт высшего профессионального образования по направлению подготовки 270800 «Строительство» (квалификация (степень) «Бакалавр») / Министерство образования и науки РФ. М.:, 2010. - С. 30. (Приказ Минобрнауки от 18.01.2010 № 54.)

2. Федеральный государственный стандарт высшего профессионального образования по направлению подготовки 270800 «Строительство» (квалификация (степень) «Магистр») / Министерство образования и науки РФ. - М., 2009. - С. 35. (Приказ Минобрнауки от 21.12.2009 № 750.)

3. Государственный образовательный стандарт высшего профессионального образования. Направление 550100 «Строительство» / Министерство образования РФ. М., 2000. - С. 34. (Приказ Министра образования от 07.03.2000 №11 тех/маг.).

\section{References}

1. Federal'nyy gosudarstvennyy standart vysshego professional'nogo obrazovaniya po napravleniyu podgotovki 270800 Stroitel'stvo (kvalifikatsiya (stepen') «Bakalavr») [Federal government standard of higher education in the direction of training Building 270800 (qualification (degree) "Bachelor")]. Moscow: Ministerstvo obrazovaniya i nauki RF, 2010. 30 p. (Prikaz Minobrnauki ot 18.01.2010, no. 54.)

2. Federal'nyy gosudarstvennyy standart vysshego professional'nogo obrazovaniya po napravleniyu podgotovki 270800 Stroitel'stvo (kvalifikatsiya (stepen) «Magistr») [Federal government standard of higher education in the direction of training Building 270800 (qualification (degree) "Master")]. Moscow: Ministerstvo obrazovaniya i nauki RF, 2009, 35.p. (Prikaz Minobrnauki ot 21.12.2009, no. 750.) 
3. Gosudarstvennyy obrazovatel'nyy standart vysshego professional'nogo obrazovaniya. Napravlenie 550100 Stroitel'stvo [State educational standard of higher education. 550100 Construction Direction]. Moscow: Ministerstvo obrazovaniya RF, 2000, 34 p. (Prikaz Ministra obrazovaniya ot 07.03.2000, no. 11 tekh/mag.)

\section{Об авторах}

Полищук Анатолий Иванович (Краснодар, Россия) - доктор технических наук, профессор, заведующий кафедрой «Основания и фундаменты» Кубанского государственного аграрного университета; e-mail: ofpai@mail.ru

Маршалка Андрей Юрьевич (Краснодар, Россия) - кандидат технических наук, старший преподаватель кафедры «Основания и фундаменты» Кубанского государственного аграрного университета; e-mail: a.marshalka@mail.ru

\section{About the authors}

Polyschuk Anatoliy Ivanovich (Krasnodar, Russian Federation) Doctor of Technical Sciences, Professor, Head of Department of Bases and foundations, Kuban State Agrarian University; e-mail: ofpai@mail.ru

Marshalka Andrey Yur'evich (Krasnodar, Russian Federation) Ph.D. in Technical Sciences, Assistant Professor, Department of Bases and foundation, Kuban State Agrarian University; e-mail: a.marshalka@ mail.ru

Получено 03.04.2014 